\title{
Construction methods used for controlling temperature in mass concrete structures
}

\author{
Mohamed Abdel-Raheem ${ }^{\mathrm{a} *}$, Ofsman Quintana ${ }^{\mathrm{a}}$, Melissa Morales ${ }^{\mathrm{a}}$, Yahaira Marroquin-Villa ${ }^{\mathrm{a}}$, \\ Dalinda Ramos ${ }^{\mathrm{a}}$, Sylvia Hernandez ${ }^{\mathrm{a}}$
}

${ }^{a}$ Civil Engineering Department, University of Texas Rio Grande Valley, Edinburg, Texas 78539, USA

\begin{abstract}
The hydration of cement can release a substantial amount of heat that can be problematic in mass concrete structure. This heat of hydration $(\mathrm{HH})$ can produce thermal stresses that can crack the concrete and compromise the integrity of the structure leading to its failure. Throughout the years, different methods have been developed in order to mitigate the negative effects of the HH on mass concrete structures. This study presents a comprehensive review of the previous methods documented in the literature that have been utilized in controlling the temperature rise due to the $\mathrm{HH}$ in mass concreting. The reviewed methods were divided into two main categories, namely supplementary material and construction methods. This paper focuses on the different methods of construction that are used to control the temperature rise in mass concrete structures. The paper also presents an analysis of these methods using findings from previous studies.
\end{abstract}

(C) 2018 The Authors. Published by Diamond Congress Ltd., Budapest University of Technology and Economics Peer-review under responsibility of the scientific committee of the Creative Construction Conference 2018.

Keywords: Heat of hydration; mass concrete; cooling pipes, construction methods

\section{Introduction}

A common problem with the construction of mass concrete structures is the additional money, time, and efforts needed to deal with the heat of hydration $(\mathrm{HH})$ released. The $\mathrm{HH}$ occurs as a result of the exothermic reaction between cement and water. This reaction causes a rise in the temperature inside the mass concrete structure, which creates a temperature gradient between the interior of the structure and its surface. Temperatures in the interior can reach up to $135^{\circ} \mathrm{F}$ depending on the size of the structure and the mass of concrete. The greater the mass of concrete, the higher the temperature will be. Most codes specify a temperature difference between the surface and the core of the concrete less than $35^{\circ} \mathrm{F}$ [1]. If this difference is surpassed, thermal cracking in the concrete may occur.

Thermal cracking is the result of the concrete surface and core expanding and contracting at different rates. The concrete expands as the temperature increases due to the release of the $\mathrm{HH}$. However, the surface of the concrete structure cools faster than its core [2]. The heat in mass concrete escapes at a slower rate than is generated, which keeps the core hot and creates problems in the structure. Durability and strength are crucial in mass concrete structures, therefore the heat gradient that causes thermal cracking must be prevented and controlled. Proper placement of concrete and mix design are the best options when trying to reduce the heat released. For example, in normal concrete placement for isolated footings, the heat is dissipated into the soil without creating any temperature change in the structure. However, thermal cracking is extremely problematic in mass concrete structures, such as matt foundations, and can cause a lot of damage [2] . 
Mass concrete structures are structures with large concrete contents, such as dams, mat foundations, thick slabs, piers, and structural columns. It is defined by the American Concrete Institute as "any volume of concrete with dimensions large enough to require that measures be taken to cope with the generation of heat from hydration of the cement and attendant volume change to minimize cracking." The general rule is that any concrete element that has its smallest dimension 3 feet or more should be considered a mass concrete member. However, small concrete elements with high content of cement or cement Type III can be also considered mass concrete member due to the high amount of $\mathrm{HH}$ released [3]

\section{Problem and objective}

Several previous studies have investigated different methods for treating the effects of the HH. The body of knowledge in this area requires proper organization to facilitate the process of reviewing the literature for future researchers. As such, this paper aims at presenting organized summaries of previous studies conducted on different methods used for treating the $\mathrm{HH}$ in mass concreting. The main focus of this paper is the construction methods used for controlling the temperature in mass concreting as will be discussed in detail in the following sections.

\section{Methodology}

The methodology implemented in this research started with a comprehensive review and acquisition of all previous work and publications that discussed the methods used for treating the HH in mass concreting, particularly the construction methods. Then the focus was on the development of a classification system that categorizes previous work conducted on the treatment of the $\mathrm{HH}$ in a manner that reflect the nature of the work. Two categories were defined, as shown in Figure 1. The first one includes all the studies conducted on the treatment of the HH in mass concreting using construction methods. The second category includes the studies conducted on the effect of using different supplementary materials (SM) used in mass concreting to treat the $\mathrm{HH}$, as shown in Fig, 1. The common research objective among the studies in the first category focuses on mitigating the negative effects of the HH by controlling the temperature of concrete. On the other hand, the studies of the second categories aimed at minimizing the amount of heat released during the hydration of cement through chemical reactions with supplementary materials.

\section{Methods of reducing the heat of hydration}

The construction method used for treating the HH in mass concrete structures is the main focus of this study. There are several construction methods that can be used to control the temperature inside the core of the concrete structure, such as: 1) precooling of concrete aggregates, 2) post-cooling of concrete, 3) insulation of the concrete member, and 4) pouring the concrete in thin lifts.

\subsection{Precooling of Concrete}

Precooling the concrete is the process of decreasing the temperatures of either the aggregates or the mixing water or both. This can be achieved using different methods, such as storing the aggregates in the shades and continuously sprinkling the coarse aggregates with water. Another method is using cold mixing water or replacing it with ice. Also, using liquid nitrogen (LN) either by injecting it in the mixing water or the fresh concrete is a frequent method for lowering the temperature of the concrete. Cooling the aggregates is more effective than lowering the temperature of the mixing water $[3,4]$. The rule of thumb is that decreasing the temperature of aggregates by $2^{\circ} \mathrm{F}$ can lower the temperature of concrete by $1^{\circ} \mathrm{F}$. To achieve the same effect, the temperature of the mixing water should be decreased by $4^{\circ} \mathrm{F}$. The maximum reduction in the temperature of concrete that can be obtained using cold mixing water and shaved ice are $20^{\circ} \mathrm{F}$ and $10^{\circ} \mathrm{F}$ respectively $[3,4]$. Sometimes specifications limit the placement temperature of concrete to $50^{\circ} \mathrm{F}$, which means a drop of $20^{\circ} \mathrm{F}$ or more in the concrete temperature is needed. In this case, shaved ice will not be effective; the alternative would be using LN. Injecting $\mathrm{LN}$ in the concrete can lower the temperature by $35^{\circ} \mathrm{F}$ [3].

The process of injecting Liquid Nitrogen $(\mathrm{LN})$ into a cement mix starts by transporting it into a cement truck outfitted with a special tank capable of keeping the cryogenic temperature of the LN [5,6]. A truck must drive into a frame that will then be connected to a LN tank with an injection lance; the substance is then poured into the ready-mix trucks rotating drum via injection lance (which is a safe process). The truck then drives to the work site where it begins to pour the concrete mixed with LN, see Fig. 2. 
A study by Nakane et al. [7] assessed the effect of LN, air-cooling of materials before mixing, and shaved ice as a replacement of mixing water on the strength and microstructure as well as the rate of hydration of cement in concrete. The study concluded that the different cooling methods considered do not affect the strength or the rate of hydration of cement pastes in concrete. The addition of LN has no negative effect on the compressive strength of the concrete but does not improve it either.

Other studies also investigated the effect of LN on concrete properties and the HH [5,6]. The study concluded that LN does not have a significant effect on the concrete hydration or most of its properties that are independent of temperature. However, it was noticed that concrete made with LN had the same slump as hot concrete, which is substantially lower than the slump of concrete made in room temperature. Also, it was concluded that LN extends the setting time of concrete. LN is much more effective at cooling concrete than regular ice is due to its extremely low temperature of $-196^{\circ} \mathrm{C}$; also, it is readily available and inexpensive. However, there are disadvantages for the use of $\mathrm{LN}$ in concrete as well. One common concern is workers' safety, since prolonged exposure to liquid nitrogen can lead to burns and frostbite. It can also damage the rotating drum of the truck mixer because the LN makes the steel become more brittle and more prone to crack. Another concern is that LN can negatively affect the proper development of compressive strength of concrete because of the localized freezing that prevents the complete hydration of the cement.

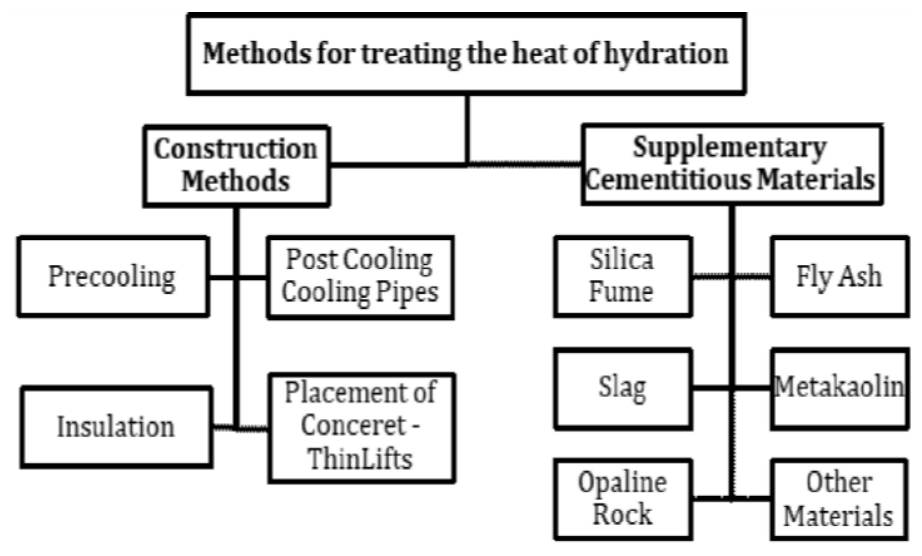

Fig. 1. Classification of different methods used for treating the $\mathrm{HH}$

An article presented a case study on the successful use of LN to cool concrete in the Turnpike project in central Texas [8]. Although the article does not report any scientific experimentations, it highlights some valuable field experiences for mixing concrete with LN. For instance, mixing concrete with LN was done on site by inserting a 6-ft lance connected to a $\mathrm{LN}$ tank in a concrete truck while the batching the concrete. The article refers to the advantages of using LN for cooling concrete over chilled water or crushed ice regarding the inconsistency in the slump obtained when using the latter methods. The article also argues that LN can be the most economic choice since it is less labor intensive compared to crushed ice, and due to the high costs of water chillers and fuel needed for cooling. The article also refers to the previous disadvantages mentioned above [5,6,8], and to the importance of conducting further experimentation to assess the effect of $\mathrm{LN}$ on different concrete properties.

\subsection{Post-Cooling of Concrete}

The cooling pipes method, typically referred to as post-cooling, has been one of the most common methods for controlling the temperature in mass concrete structures. In this method, cool water is circulated through small diameter pipes embedded in the body of the concrete structure, as shown in Fig.3. The use of cooling pipes is very popular in dam construction. Several thermal studies have been conducted to evaluate the effectiveness and drawbacks of the use of cooling pipes in mass concreting. The determination of the size of the pipes, spacing between pipes, rate of flow, and temperature of the cooling water can be a sophisticated task. This is due to the fact that there are several factors that affect the $\mathrm{HH}$ in a mass concrete structure that should be taken in consideration when designing the cooling pipe system. Some of these factors are: type of cement, supplementary material, temperature of mixing water, formwork, lift thickness and rate of placement, and climatic conditions [9]. Other factors that pertain to the design are, the type of 
pipes used, rate of flow of water, and the temperature difference between the cooling water and concrete. Usually the pipes are equipped with control valves to control the rate of flow. Also, special attention should be given to the outlet water as the discharge temperature can be high enough to compromise the safety of workers. The source of cooling water is usually public drinking supply; however, in remote areas, water trucks and onsite chillers can be used to supply and cool the water [10] (Roush \& O'Leary 2005).

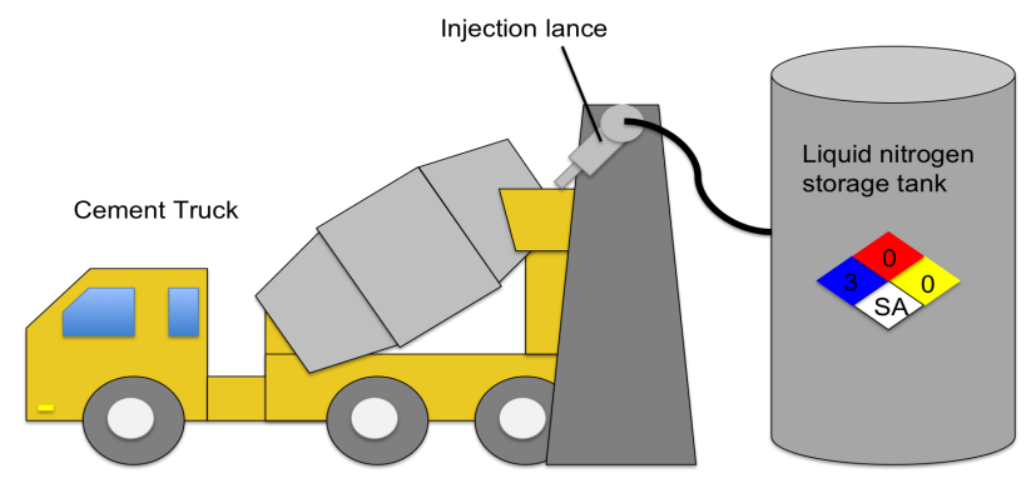

Fig. 2. Process of injecting concrete with LN using a lance connected to a LN tank. [5]

Another important factor that may affect the efficiency of the cooling pipe system in controlling the temperature of the mass concrete structure is the type of material of the pipe. Most large mass concrete structures rely on metal pipes to cool the internal temperature due to its high thermal conductivity. A study conducted by Zhu [11] illustrated the calculations formulas needed to replace metal pipe systems with nonmetal ones. The study presented different formulas for computing the radius of pipes, horizontal spacing between pipes, and the time required to decrease the temperature to a specified degree for different types of pipes. The study concluded that polythene pipes could be very convenient in the construction of mass concrete structures.

Cooling coils have been used as well to control the internal temperature of mass concrete structures. Although very costly, some have been used in larger structures such as dams as well as tunnel plugs. The concept of those cooling coils is similar to the pipes since they are also embedded in the structure. The use of a refrigeration system has also been explored with these coils. They are used to distribute ammonia liquid within a system to make ice and chilled water. The size of a structure really depends on the refrigeration system that is put in place; a dam, for example, it would require a large refrigeration system to control the internal temperature and cycle the ammonium fluid [12]. These systems would also be able to produce ice or chilled water for the desired effects [13].

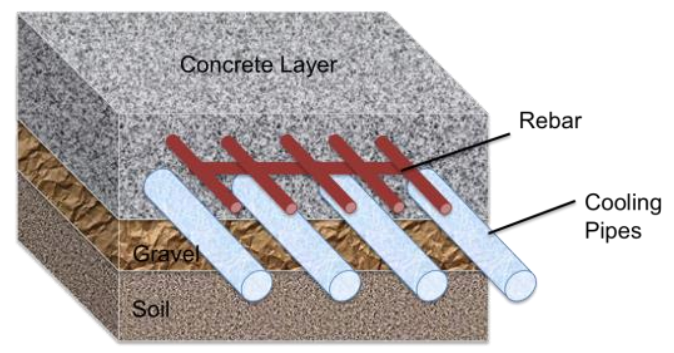

Fig. 3. A cross section of the interior of a concrete slab with cooling pipes $[2,11]$

While very few studies addressed new innovations in the cooling pipe systems used, most studies covered in the literature focused on the thermal analysis of cooling pipes. One of the most notable study is the U.S. Army Corps of Engineers technical note on the thermal studies of mass concrete structure [14]. The note classified mass concrete structures into 3 types: 1) gravity structures, such as dams and lock walls, 2) thick shell structure, such as arch dam, and 3) thick reinforced structures, such as locks, pumping stations, massive foundations, and bridge piers. In this report, thermal analysis studies were classified into three categories according to their complexity. 
The first level (L1) represents the simplest of form of thermal analysis. This level requires basic analysis based on generic assumptions. This type of analysis is suitable when the consequences of thermal cracking are insignificant, and do not affect the safety or stability of the structure. This level of analysis is appropriate at the feasibility stage and is usually used to determine control and structural joints spacing as well as the thickness of lifts. Thermal analysis at L1 can be used for diversion structure for irrigation canals, thick reinforced foundation, and massive bridge piers.

The second level (L2) requires more solid and detailed analysis of the thermal stresses in the structure using a variety of tools. This level of analysis should be conducted when thermal stresses are significant enough to be of a concern to the structure safety and stability. The analysis should be used with structures such as, gravity dams, tunnel plugs, low-head arch dam, and pumping stations.

The third level (L3) incorporates the most sophisticated level of analysis and is needed for critical structures where cracking creates major risks to the structure. The methods of analysis at this level can be very costly and time consuming. They are required for complex and new structure when little information and no prior experience are available. The L3 analysis is useful in when interaction between several stresses exists from different loading conditions. This type of analysis can be applied to gravity and some arch dams [14].

A thermal analysis study was conducted using 3D finite element analysis of a pipe cooling system embedded in a spread concrete footing. The pipe was modeled using a line element, and the internal flow theory was used for estimating the changes in the temperature of the cooling water. The footing was cooled with a pipe loop embedded in the concrete with both an inlet and outlet. The outlet values represent the heat that is being dissipated over a 10-day period while the inlet represents the lower values of the cooling water, which is responsible for moving the heat through the outlet. The results were verified to actual data from the bridge site [15].

Another thermal analysis study focused on the mass concreting in dam construction. The study considered the general laws of heat transfer (radiation, convection, and conduction) as well as the climatic factors that can affect the temperature of the concrete, such as solar radiation, and air and water temperature. Other factors that affect the HH during the construction phase are: type of formwork, time to remove formworks, and rate and thickness of lift placement. In this study, a program was developed to simulate the construction phase of the dam. A case study of Alqueva's dam was presented; the $\mathrm{HH}$ of the dam was estimated, and calculation of the construction phase was done [9].

One thermal analysis study was conducted on double-layer staggered heterogenous cooling pipes embedded in a concrete slab. The analysis was conducted using 3-D finite analysis and the equivalent equation for heat conduction. The mathematical model aimed at stimulating the temperature variations of mass concrete structure. The cement $\mathrm{HH}$ was modeled using a double exponential function, while the temperature of the outlet water was estimated using the law of conservation of energy. The results were validated using a case study of an arch dam in China that was under construction at that time [16].

Although cooling pipes are effective in controlling the temperature in mass concrete, thermal stresses can still occur inside the body of the concrete especially near the pipes. A study was conducted to simulate the propagation of thermal analysis based on particle flow code. The 2D particle flow represents aggregates and mortar using particles of different sizes and simulate the cement paste using parallel bonds. The 2D particle flow was used to model a concrete slab that has a length of 1 meter and width of $0.5 \mathrm{~m}$. The study concluded that thermal cracks might occur if the temperature of the cooling water is too low or the temperature gradient between the concrete and the cooling pipes is high. Bond breakages was observed where thermal cracks occurred [17].

One study presented a new method for controlling the concrete temperature during the construction of a large project in China. The method is based on controlling the circulation of water between a foundation slab and a mass concrete structure. The design consists of a dewatering well that travels to the natural ground and flows to a thermostat tank. It then leads to a cooling pool that is located over a foundation slab above the surface, which moves back to the natural ground and into the drainage ditch. The idea is to develop a self-sustained concrete water-cooling system using water from the dewatering process. The average temperature of a concrete slab is around $32^{\circ} \mathrm{C}$, but the study showed that the water reduced the temperature to almost $24^{\circ} \mathrm{C}$ in a 24 -hour duration of circulation. A finite element analysis of the foundation was conducted with and without the circulating water. The results were verified using actual measures from the site [18].

A major drawback that the cooling pipes have on these mass concrete structures is that, they can produce a tensile stress brought on by a sharp cooling when water is run through the pipe [19]. Should there be a massive temperature change between the surface of the pipes and the interior of the concrete, cracking will occur. At this point of cooling the creep is low while the elastic modulus is high, thus resulting in cracking from the inside. Temperature control is an expected factor to prevent this. 


\subsection{Insulation}

Insulation is another method that has been used for reducing thermal cracking. The surface of the concrete is insulated to decrease the rate of cooling, see Fig. 4; hence, minimize temperature gradient between the surface and core of concrete [4]. It is important to note that thermal cracking is caused by the large temperature difference between the interior and surface of the mass concrete structure. As concrete cools, it starts to shrink. The resulting temperature from heat of hydration can exceed the temperature of the immediate environment. Insulation assists in maintaining the same shrinkage rate for the surface and the core of concrete, which prevents thermal cracking. Insulation is inexpensive, but must be in place for a long time. This can lead to prolonged construction durations, which cost additional money. The materials used for insulation can come in many forms, but it all depends on how much the temperature needs to be reduced $[2,20]$.

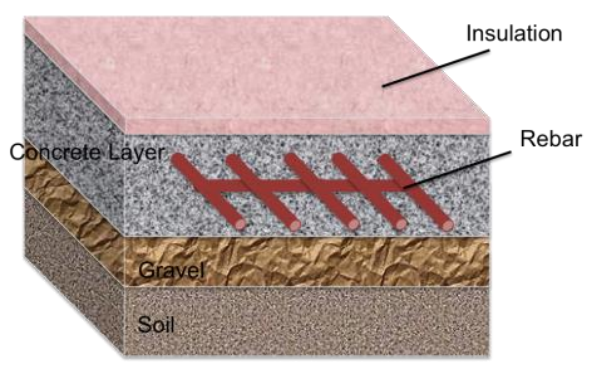

Fig. 4. Insulation of a mass concrete member

\section{Findings}

The review of the literature shows that there are very few construction methods that can be used for controlling the temperature in mass concreting. However, there are still some concerns about the efficiency and the potential risks that these methods have on concrete. For instance, the utilization of cooling pipes might lead to thermal cracking at the locations where the pipes are embedded if the temperature of the cooling water is not appropriately controlled. Some concerns are also raised regarding the impact of LN on the drums of the concrete truck mixers; and insulation requires very long time, which might render it expensive. The literature did not include any comparative analysis, financial feasibility evaluation, life cycle assessment, or life cycle cost analysis of the methods addressed above. A rough analysis would reveal that $\mathrm{LN}$ can be the best choice among the available construction methods due to its effectiveness at cooling the concrete, and cheap price. LN does not require any effort or special preparation except for the special lining of the drum of the concrete mixer; it only needs to get injected into the mix before pouring. Although cooling pipes are good for large structures, they are expensive when compared to liquid nitrogen, and requires continuous monitoring of the cooling water temperature and rate of flow. The advantages and disadvantages of the construction methods that were explored are shown in Table 1. 
Table 1: Comparison of construction methods used for controlling temperature in mass concreting

\begin{tabular}{|c|c|c|}
\hline Construction Methods & Advantages & Disadvantages \\
\hline Cooling Pipes & $\begin{array}{l}\text { - Effective for large structures } \\
\text { (dams) }\end{array}$ & $\begin{array}{l}\text { - Expensive } \\
\text { - Might lead to thermal cracking around } \\
\text { the pipes }\end{array}$ \\
\hline Liquid Nitrogen & $\begin{array}{l}\text { - Effective at cooling } \\
\text { - Readily available } \\
\text { - Cheap }\end{array}$ & $\begin{array}{l}\text { - Concrete strength may not develop } \\
\text { properly due to localized freezing } \\
\text { - Needs special lining for the concrete } \\
\text { mixer }\end{array}$ \\
\hline Insulation & - Inexpensive & $\begin{array}{l}\text { - Not as effective as other methods } \\
\text { - Requires longer durations }\end{array}$ \\
\hline
\end{tabular}

\section{Conclusion}

This paper presented a thorough review of the different construction methods used to control temperature in mass concrete structures. The paper presented concise summaries of previous studies and publication that focused on the construction methods used for controlling the HH. The majority of the studies conducted focused on thermal analysis of cooling pipes of different arrangement, materials, flow rates, and cooling water temperatures. The review shows that liquid nitrogen is a cheap and effective way of reducing the $\mathrm{HH}$. While cooling pipes can be very effective in dam construction, it is very costly and there are concerns about the posing risks to the integrity of the structure. Most error associated with these methods can be avoided by having experienced engineers and personnel to monitor the progress of the concrete structure. In addition, some method works best for certain locations, because climate does play a role in curing of cement. Some areas that are colder would benefit more by using the insulation method, and locations with warmer climate should use the cooling pipe method and Liquid Nitrogen injection method. The paper should prove useful in providing a recent review for the current construction methods used in controlling temperature and treatment of $\mathrm{HH}$ in mass concrete structures.

\section{References}

[1] Portland Cement, Concrete, and Heat of Hydration. (1997, July). Concrete Technology Today, 18(2), 1-4. Retrieved July, 2014, from http://cement.org/tech/pdfs/p1972.pdf

[2] J. Gajda (n.d.), Mass Concrete-How Do You Handle the Heat? Retrieved May 12, 2016, from http://www.cement.org/for-concrete-bookslearning/concrete-technology/concrete-designproduction/mass-concrete

[3] K. Basham, How To Plan and Manage Curing for Mass Concrete Pours (2014). Retrieved March 25, 2016, from http://www.forconstructionpros.com/concrete/equipment-products/article/11598829/how-to-plan-and-manage-curing-for-mass-concrete-pours

[4] A. Patil, Heat of Hydration in the Placement of Mass Concrete. International Journal of Engineering and Advanced Technology (IJEAT) ISSN: 2249 - 8958, Volume-4 Issue-3, February 2015

[5] J. Hema, Effects of Liquid Nitrogen on concrete hydration, microstructure and properties. University of Texas at Austin, 2007.

[6] M. Juenger, J. Hema, S. Solt, Effects of Liquid Nitrogen on concrete hydration, microstructure and properties. Center for Transportation Research, University of Texas at Austin, 2007.

[7] Nakane, S., Saito H., Ohike, T., Strength development and microstructure of cement and concrete precooled with liquid nitrogen, Proceedings of the international conferenceo on concrete in hot Climates, Concrete in hot Climates, 1992.

[8] W. Beaver, Liquid Nitrogen for Concrete Cooling. Concrete International, 2004.

[9] E. Castilho, N. S. Leitão, C. Tiago, Thermal analysis of concrete dams during construction, second international dam world conference, Lisbon, Portugal, 2015

[10] K. Roush, J. O’Leary, Cooling concrete with embedded pipes. Concrete international, 27(1), 2005, pp 30-32.

[11] B. Zhu, Effect of cooling by water flowing in nonmetal pipes embedded in mass concrete. Journal of construction engineering and management, 125(1), 1999, pp 61-68.

[12] G. C. Briley, Cooling for Dams. ASHRAE Journal, 46(3), 2004, pp 66.

[13] Bureau of Indian Standards. Temperature control of mass concrete for dams - Guidelines. Indian Standard, 1999.

[14] Department of The Army U.S., Army Corps of Engineers. Thermal studies of mass concrete structures. (Technical Letter No. 1110-2-542), 1997.

[15] S. G. Kim, Effect of heat generation from cement hydration on mass concrete placement, 2010.

[16] Yang, J., Hu, Y., Zuo, Z., Jin, F., \& Li, Q. Thermal analysis of mass concrete embedded with double-layer staggered heterogeneous cooling water pipes. Applied Thermal Engineering, 35, 2012, pp145-156.

[17] Li, L., Liu, X., Dao, V. T., \& Cheng, Y. Thermal cracking analysis during pipe cooling of mass concrete using particle flow code. Advances in Materials Science and Engineering, 2016. 
[18] Liu, W., Cao, W., Yan, H., Ye, T., \& Jia, W. Experimental and Numerical Studies of Controlling Thermal Cracks in Mass Concrete Foundation by Circulating Water. Applied Sciences, 6(4), 2016, pp 110.

[19] Qui Y., Zhung G. Stress and Damage in Concrete Induced by Pipe cooling at Mesoscopic Scale. Advances in Mechanical Engineering Vol. 9 (2), 2017 pp 1-17.

[20] Gajda, J., \& Vangeem, M. . Controlling temperatures in mass concrete. Concrete international, 24(1), 2002, pp 58-62, 2002. 